\title{
High burden and frailty: association with poor cognitive performance in older caregivers living in rural areas
}

\author{
Sobrecarga elevada e fragilidade: relação com baixo desempenho cognitivo em \\ idosos cuidadores moradores de comunidades rurais
}

\begin{abstract}
Allan Gustavo Brigola, ${ }^{1}$ Bruna Moretti Luchesi, ${ }^{2}$ Tiago da Silva Alexandre, ${ }^{2}$ Keika Inouye, ${ }^{2}$ Eneida Mioshi, ${ }^{3}$
\end{abstract}
Sofia Cristina Iost Pavarini ${ }^{2}$

\begin{abstract}
Introduction: Older caregivers living in rural areas may be exposed to three vulnerable conditions, i.e., those related to care, their own aging, and their residence context.

Objective: To analyze the association of burden and frailty with cognition performance in older caregivers in rural communities. Method: In this cross-sectional survey, 85 older caregivers who cared for dependent elders were included in this study. Global cognition (Addenbrooke's Cognitive Examination - Revised; Mini Mental State Examination), burden (Zarit Burden Interview) and frailty (Fried's frailty phenotype) were assessed. All ethical principles were observed.

Results: Older caregivers were mostly women (76.7\%); mean age was 69 years. Cognitive impairment was present in $15.3 \%$, severe burden in $8.2 \%$, frailty in $9.4 \%$, and pre-frailty in $52.9 \%$ of the older caregivers. More severely burdened or frail caregivers had worse cognitive performance than those who were not, respectively (ANOVA test). Caregivers presenting a high burden level and some frailty degree (pre-frail or frail) simultaneously were more likely to have a reduced global cognition performance.

Conclusion: A significant number of older caregivers had low cognitive performance. Actions and resources to decrease burden and physical frailty may provide better cognition and well-being, leading to an improved quality of life and quality of the care provided by the caregivers.
\end{abstract}

Keywords: Aged care, caregivers, frail elderly, cognition, rural population.

\section{Resumo}

Introdução: Idosos cuidadores que moram em comunidades rurais podem estar expostos a uma tripla condição de vulnerabilidade, por exemplo, condições relacionadas a ser cuidador de outro, condições inerentes ao seu próprio envelhecimento e ao seu contexto de moradia.

Objetivo: Analisar a associação entre sobrecarga, fragilidade e desempenho cognitivo em idosos cuidadores que moram em comunidades rurais.

Método: Tratou-se de uma pesquisa transversal com 85 idosos cuidadores que cuidavam de idosos dependentes na comunidade. A cognição global (Exame Cognitivo de Addenbrooke - Revisado; Mini Exame do Estado Mental), a sobrecarga (Entrevista de Sobrecarga de Zarit) e a fragilidade (Fenótipo de Fragilidade de Fried) foram mensuradas. Todos os princípios éticos foram respeitados.

Resultados: Os idosos cuidadores foram predominantemente mulheres (76.7\%) com média de idade de 69 anos. A proporção de indício de alteração cognitiva foi de $15.3 \%$, sobrecarga severa de $8.2 \%$, fragilidade de $9.4 \%$ e pré-fragilidade de $52.9 \%$ nos idosos cuidadores. Cuidadores severamente sobrecarregados ou frágeis apresentaram pior desempenho cognitivo comparado àqueles levemente sobrecarregados e não frágeis, respectivamente (teste ANOVA). Apresentar simultaneamente sobrecarga elevada e algum grau de fragilidade (pré-frágil ou frágil) esteve associado à redução do desempenho cognitivo global.

Conclusão: Um significante número de idosos cuidadores teve indício de alteração cognitiva. Estratégias e recursos para reduzir o sentimento de sobrecarga e a fragilidade física podem melhorar o desempenho mental e o bem estar, levando assim a uma melhora da qualidade de vida do idoso que cuida, bem como a qualidade do cuidado prestado por ele.

Descritores: Cuidado a idosos, cuidadores, idoso frágil, cognição, população rural.

\footnotetext{
${ }^{1}$ Programa de Pós-Graduação em Enfermagem, Universidade Federal de São Carlos, São Carlos, SP, Brazil. 2 Departamento de Gerontologia, Universidade Federal de São Carlos, São Carlos, SP, Brazil. ${ }^{3}$ Faculty of Medicine and Health Sciences, School of Health Sciences, University of East Anglia, Norwich, United Kingdom. This study was based on the dissertation entitled "Perfil cognitivo, fragilidade, sintomas depressivos e sobrecarga de idosos cuidadores em comunidades rurais," presented at Programa de Pós-Graduação em Enfermagem (Mestrado em Ciências da Saúde), Universidade Federal de São Carlos, São Carlos, SP, Brazil. Submitted Dec 13 2016, accepted for publication May 252017.

Suggested citation: Brigola AG, Luchesi BM, Alexandre TS, Inouye K, Mioshi E, Pavarini SCI. High burden and frailty: association with poor cognitive performance in older caregivers living in rural areas. Trends Psychiatry Psychother. 2017;39(4):257-263. http://dx.doi.org/10.1590/2237-6089-2016-0085
} 


\section{Introduction}

Chronic stress, depression and anxiety are consequences of daily caring and may contribute to impaired mental health, well-being and caregiver cognitive performance. ${ }^{1}$ These effects decrease the quality of care. Meta-analyses have shown that caregivers have higher levels of depression and burden and lower levels of subjective well-being and perceived health, especially women and spouses. Moreover, these caregivers report more care-recipient behavioral problems, experience more hours of care, help in more activities and take care of elders in a more personal way compared with children or children-in-law. ${ }^{2-4}$

Routine work requires judgment and problemsolving skills from caregivers, imposing a minimum level of cognitive performance as a requirement. A review verified that caregivers may have cognitive difficulties, particularly in processing speed functions, working memory, executive function and delayed memory. Hence, cognitive performance restrictions in caregivers compromises self-care and their ability to care for others, affecting the adoption of adequate health practices. ${ }^{5}$

Additionally, older people might experience frailty. The frail phenotype (weight loss, exhaustion, weakness, slowness, low physical activity) has been associated with cognitive decline. ${ }^{6}$ Some studies showed the importance of assessing frailty in older people, including older caregivers, since it might predict disability, dementia and death. ${ }^{7-9}$

Some complicating factors related to caregiving should be highlighted, e.g., being over 60 years old and living on non-urban areas, where formal support is more difficult to be found. Data from the Brazilian Institute of Geography and Statistics (Instituto Brasileiro de Geografia e Estatística - IBGE) show that, in 2013 , about $16 \%$ of elderly people were living in rural communities and regions. ${ }^{10}$ In addition, approximately $13 \%$ presented impairment of activities of daily living (ADLs) due to health issues. Lastly, the prevalence of moderate functional disability increases with age. ${ }^{11}$

Similarly to urban areas, caregiving is informal and mostly offered by family members in rural areas, as shown by data from the Brazilian National Household Survey (Pesquisa Nacional por Amostra de Domicílios - PNAD). ${ }^{11}$ However, compared to urban areas, the support network in rural settings has been considered to be predominantly frail and informal. ${ }^{12}$

Regarding studies in rural areas, two reviews found few scientific studies conducted with caregivers. In addition, they were limited to describing their samples. ${ }^{13,14}$ The way how care is provided to elders is still poorly understood in rural areas, as are the factors that affect cognition performance in older people who provide care for others. This study is justified by the need to identify factors associated with cognitive performance, which significantly compromises the quality of care delivered to the recipient, as well as the caregiver's self-care. Even though frailty is known to influence cognitive performance, older caregivers experience other factors that aggravate cognitive performance, such as burden stress. Rural older caregivers may be exposed to three vulnerable conditions, i.e., those related to care (burden), their own aging (frailty), and their residence context, since they are living far from formal care support (rural areas). Thus, the present study aimed to analyze the association of burden and frailty with cognition in elders who provide daily and essential care for the survival of other seniors in a rural context.

\section{Methods}

\section{Participants}

This was a cross-sectional study that included 85 older caregivers who cared at home for a dependent elder living in the community. This study is a part of a broader project entitled "Variables associated with cognition in older caregivers," developed by the Aging and Health Research Group at Universidade Federal de São Carlos, Brazil. ${ }^{15}$ This study analyzed a sample of older caregivers (age $\geq 60$ years) who were living in the community and were registered in one of the 18 primary health care centers in São Carlos. The city is located in southeastern Brazil and has an estimated population of 221,950 inhabitants (records for year 2010). ${ }^{10}$

Older caregivers who met the study's inclusion criteria were invited to participate. Inclusion criteria were: 1 ) being 60 years old or older; 2) being a user of primary care services in the city; and 3) caring for a dependent older person (age $\geq 60$ ) living in the same house. In order to be considered dependent, the care recipient had to be dependent in at least one of the ADLs/instrumental ADLs (IADLs) assessed by the Katz Index ${ }^{16}$ and by Lawton and Brody's Scale. ${ }^{17}$

A list provided by two primary care centers located in rural areas was used to identify households within the covered area that had at least two elders living together. The initial number of households was 115, but in three of them one of the elders was dead. In another three, the elders moved to a new address; and in 15 , they were not found at home after three visits. The remaining 94 households were therefore visited, and the objectives of the study were explained to the resident elders. The elders of six residences were 
excluded because they refused to participate in the study. All the elders living in the 88 residences included (response rate $76.5 \%$ ) were assessed regarding their performance in ADLs and IADLs. Three more residences were excluded at this stage because all the elders were independent in their ADLs and IADLs. In the remaining residences, couples composed of an older caregiver and a dependent care recipient were identified, and these couples comprised the final sample of older caregivers caring for a dependent care recipient at home in rural areas $(n=85)$.

\section{Data collection}

Before answering the questionnaires, participants consented to the study, in compliance with the Declaration of Helsinki. Ethical approval for the research protocol was obtained from the ethics committee of Universidade Federal de São Carlos (protocol no. 517182). The privacy of participants was preserved. Household interviews were conducted by professionals trained in the fields of gerontology and nursing.

The following variables of interest were investigated:

- Caregiver characteristics: age, gender, marital status (with partner or without partner), education and monthly family income (in Brazilian reais, in minimum wages; one minimum wage $=R \$ 724$ - approximately US\$229). Elderly caregiver age and gender were used as control variables.

- Care characteristics: relation to the person cared for (spouse, child, child-in-law, brother/sister, other), time spent daily as a caregiver. The latter variable was used as a continuous variable.

- Cognitive screening: two scales were used for the assessment of cognitive abilities, namely, Addenbrooke's Cognitive Examination - Revised (ACE-R) (attention/orientation, memory, verbal fluency, language and visuospatial abilities) ${ }^{18}$ and the Mini Mental State Examination (MMSE). ${ }^{19}$ ACE-R and MMSE scores range from 0 to 100 and from 0 to 30, respectively. Different cutoffs for different levels of formal education were used for MMSE: participants with $\geq 9$ years of literacy had a cutoff of 26/30; those with 5-8 years of literacy, a cutoff of $24 / 30$; those with 1-4 years of literacy, a cutoff of 22/30; and illiterate participants had a cutoff of $17 / 30 . .^{20}$ ACE-R continuous scores were used for comparison and regression analyses.

- Burden related to care: this variable was assessed using the Zarit Burden Interview $(\mathrm{ZBI}){ }^{21}$ which contains 22 items and is aimed to assess caregiver burden related to functional deficits at home. Final scores range from 0 to 88 , with higher scores representing more burden.
The scores were classified as follows: $0-20=$ mild burden; $21-40=$ moderate burden; and 41-88 = severe burden (median $\leq 16$ ). In the final regression model, this variable was entered as a categorical variable, using the median as the cutoff point.

- Frailty phenotype: this variable was assessed using the five-item criteria, namely, unintentional weight loss in the last year, exhaustion in the past week, muscle weakness, slowness, and decreased physical activity level compared to the previous year. Unintentional weight loss in the past year, exhaustion in the past week and decreased physical activity level were selfreported. Muscle weakness was assessed using a handgrip dynamometer, and slowness by measuring the time to walk 4.6 meters. Based on Fried's phenotype, the number of areas affected represent different levels of frailty: frail (3-5 items), pre-frail (1-2 items), and non-frail/ robust (negative responses on all five factors). ${ }^{9}$

\section{Data analysis}

Stata $10 \AA$ program was used for data analysis. The dependent variable was cognition. Since cognition presented normal distribution (assessed by the ShapiroWilk test), it was analyzed as continuous variable.

Analysis of variance (ANOVA) with post-hoc test, the $t$ test and the chi-square test were used to perform comparisons. Men and women were compared in terms of sociodemographic characteristics, context of care, cognition, burden and frailty. Frailty groups (frail, pre-frail, non-frail) and burden groups (mild, moderate, severe) were compared regarding cognition. Linear regression analysis was used to analyze factors (categorical variables) associated with cognition (continuous variable). Associations showing $p \leq 0.2$ in the univariate analyses were selected and subsequently selected using a stepwise approach. Associations showing $p \leq 0.05$ in the multiple analyses remained in the final model. Age and gender were used as control variables.

\section{Results}

\section{Characteristics}

Older caregivers were mostly female (76.7\%). Mean age was 69 years and the most prevalent age group was 60-69 years. They had a mean of 4.3 years of literacy; most were married or lived with a partner. Regarding gender, male caregivers were about 4 years older than women, and $80 \%$ of men were aged between 60 and 79 years. 
Table 1 presents sample characteristics. Regarding the context of care, most were taking care of their spouses, had been doing so for a mean of 12 years, and received help for care. No statistical differences were observed between male and female caregivers with regard to care context information.

\section{Burden, frailty and cognitive performance}

Caregivers presented mild to moderate burden. No significant differences were found between men and women, but $15 \%$ of the men were classified as severely burdened, vs. $6.2 \%$ of the women. Considering the frailty classification, most were pre-frail, following by non-frail. Among the male caregivers: $15 \%$ were frail, $45 \%$ were pre-frail, and $40 \%$ were non-frail/robust; among women, $7.7 \%$ were frail, $55.4 \%$ were pre-frail, and $36.9 \%$ were non-frail. No differences between genders were seen. Among the frailty factors assessed,

Table 1 - Participants' demographic characteristics and context of care information, São Carlos, Brazil, $2014(n=85)$

\begin{tabular}{lc}
\hline Characteristics & \% or mean $\mathbf{\text { SD }}$ \\
\hline Age (years) & $69.0 \pm 6.8$ \\
$\geq 60$ to $<70$ & 63.5 \\
$\geq 70$ to $<80$ & 24.7 \\
$\geq 80$ & 11.8 \\
& \\
Education (years) & $4.3 \pm 3.7$ \\
Illiterate & 4.7 \\
$\geq 1$ to $<5$ & 77.6 \\
$\geq 5$ to $<9$ & 5.9 \\
$\geq 9$ & 11.9 \\
& \\
Living with partner & 95.3 \\
Not living with partner & 4.7 \\
& \\
Income (R\$) & \\
$<1$ MW & $2,795.4 \pm 2,037.48$ \\
$\geq 1$ to $<2$ MW & 4.7 \\
$\geq 2$ MW & 25.9 \\
Familial relationship & 63.5 \\
Spouse & \\
Child & \\
Child-in-law & \\
Brother/sister & 89.4 \\
Other & 4.7 \\
Time of care (months) & 1.2 \\
Receives help & 3.5 \\
Does not receive help & 1.2 \\
\hline & \\
& \\
& \\
&
\end{tabular}

$\mathrm{MW}=$ minimum wages $(\mathrm{R} \$ 724.00$ - approximately US\$229); SD = standard deviation. decreased physical activity was the most frequent one, followed by unintentional weight loss (Table 2). Frailty factor frequencies were similar among men and women. Likewise, no differences were found between men and women on cognition test scores and cognitive impairment screening.

\section{Association of burden and frailty with cognitive performance}

Statistical differences were found in the cognitive scores of older caregivers with different frailty levels: attention/orientation $\quad(F=4.2 ; \quad p=0.01)$, memory $(F=15.1 ; p<0.00)$, verbal fluency $(F=6.8 ; p<0.00)$, language $\quad(F=17.3 ; p<0.00)$, visuospatial abilities $(F=7.4 ; p<0.00)$, ACE-R $(F=16.6 ; p<0.00)$ and MMSE $(F=12.8 ; \quad p<0.00)$. All cognitive scores were, in average, worse among frail caregivers. Mean cognitive performance was higher among pre-frail caregivers, even though this group performed worse than the non-frail/robust group, which showed better cognitive performance (Figure 1, part A). Cognitive scores, except verbal fluency, in different burden levels were statistically different, as follows: attention/orientation ( $F=5.3$; $p<0.00)$, memory $(F=6.5 ; p<0.00)$, verbal fluency $(F=1.8 ; p=0.16)$, language $(F=7.9 ; p<0.00)$, visuospatial

Table 2 - Participants' cognition, frailty and burden variables, São Carlos, Brazil, $2014(n=85)$

\begin{tabular}{lc}
\hline Cognition, frailty, burden & \% or mean \pm SD \\
\hline Attention/orientation & $14.7 \pm 2.4$ \\
Memory & $16.5 \pm 5.4$ \\
Verbal fluency & $6.6 \pm 2.6$ \\
Language & $19.6 \pm 5.1$ \\
Visuospatial abilities & $11.2 \pm 2.9$ \\
MMSE & $24.4 \pm 3.6$ \\
ACE-R & $68.7 \pm 15.5$ \\
Cognitive impairment indicator & 15.3 \\
& \\
Frailty & \\
Unintentional weight loss & 23.5 \\
Fatigue/exhaustion & 11.8 \\
Muscular weakness & 12.9 \\
Slow walk & 9.4 \\
Decreased physical activity & 47.1 \\
Non-frail & 37.6 \\
Pre-frail & 52.9 \\
Frail & 9.4 \\
& \\
Zarit Burden Interview & $18.4 \pm 14.2$ \\
Mild burden & 67.1 \\
Moderate burden & 24.7 \\
Severe burden & 8.2 \\
\hline
\end{tabular}

ACE-R = Addenbrooke's Cognitive Examination - Revised; MMSE = Mini Mental State Examination; SD = standard deviation. 
abilities $(F=6.3 ; p<0.00)$, ACE-R $(F=8.8 ; p<0.00)$ and MMSE $(F=7.4 ; p<0.00)$. Mean cognitive scores were worse in caregivers with moderate and severe burden, but no difference was found between both moderate and severe burden levels, regarding cognitive performance. Moreover, mean cognitive performance was higher among caregivers with mild burden (Figure 1 part B). Figure 1 summarizes post-hoc differences in ACE-R total scores according to frailty and burden levels.

Significant associations were observed between the studied variables and cognition. Pre-frailty was associated with a decrease in the adjusted model, and being frail caused a decline of around $30 \%$ in ACE-R scores when analyzed individually. Additionally, in both models, burden was associated with decreased cognitive performance, and the association was stronger when burden was analyzed independently of other variables. Burdened caregivers (ZBI $\geq 16$ ) showed a decline of $7.8 \%$ in battery test scores, as shown in Table 3. Furthermore, advanced age was associated with cognition decrease. Nevertheless, this association was seen only in simple model. Education was a major influencing factor and predictor of the score obtained in the cognitive battery for both models.

The median ZBI score, set to 16 points, was sensitive to identify caregivers who were above this cutoff ( $50 \%$ of the sample) and revealed a decrease in cognitive performance, strongly suggesting that caregiver burden is a risk factor for worse cognitive function. Comparing different levels of burden, 32.9\% of the sample was above 20 points, which was classified as moderate-severe burden. This group had worse cognitive performance (Figure 1).
A)

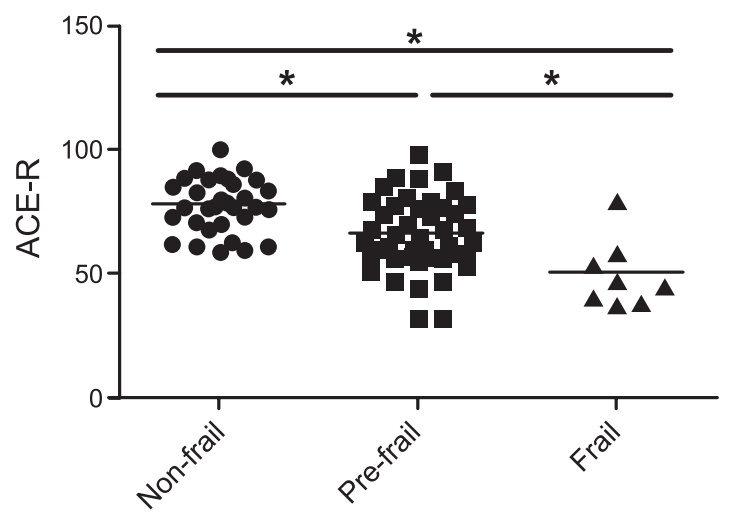

B)

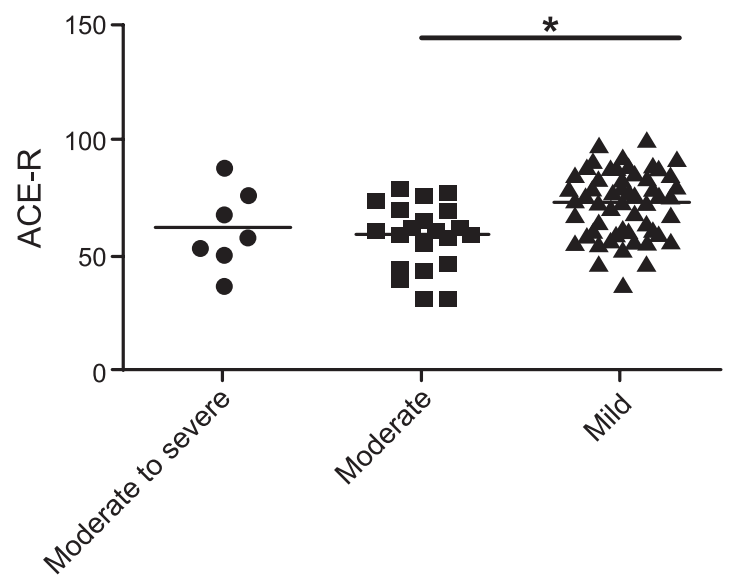

Figure 1 - Caregivers' cognition scores stratified by A) frailty and B) burden levels, São Carlos, Brazil, 2014. ACE-R = Addenbrooke's Cognitive Examination - Revised. * p-value $<0.01$.

Table 3 - Regression analyses for cognition: association between burden, frailty and cognition, controlling for gender, age and education, São Carlos, Brazil, 2014

\begin{tabular}{lcccccc}
\hline \multirow{2}{*}{$\begin{array}{l}\text { ACE-R } \\
\text { max score 100) }\end{array}$} & \multicolumn{3}{c}{ Simple model } & \multicolumn{3}{c}{ Adjusted model } \\
\cline { 2 - 7 } & $\boldsymbol{\beta}$ & $\mathbf{S E}$ & $\mathbf{P}$ & $\boldsymbol{\beta}$ & $\mathbf{S E}$ & $\mathbf{p}$ \\
\hline Gender (female) & 2.5 & 3.9 & 0.53 & 0.2 & 2.94 & 0.94 \\
70-79 years & -4.5 & 3.8 & 0.24 & 1.4 & 2.9 & 0.61 \\
$\geq 80$ years & -14.1 & 5.1 & $<\mathbf{0 . 0 1}$ & -1.4 & 3.9 & 0.72 \\
5-8 years of education & -6.6 & 6.8 & 0.34 & -8.2 & 5.9 & 0.16 \\
1-4 years of education & -22.9 & 4.2 & $<\mathbf{0 . 0 1}$ & -21.3 & 3.6 & $<\mathbf{0 . 0 1}$ \\
Illiterate & -42.7 & 7.4 & $<\mathbf{0 . 0 1}$ & -36.0 & 6.6 & $<\mathbf{0 . 0 1}$ \\
Pre-frail & -11.9 & 3.0 & $<\mathbf{0 . 0 1}$ & -8.6 & 2.5 & $<\mathbf{0 . 0 1}$ \\
Frail & -28 & 5.2 & $<\mathbf{0 . 0 1}$ & -22.3 & 4.5 & $<\mathbf{0 . 0 1}$ \\
Burden (ZBI $\geq 16)$ & -7.8 & 3.2 & $\mathbf{0 . 0 2}$ & -4.8 & 2.3 & $\mathbf{0 . 0 4}$ \\
\hline
\end{tabular}

ACE-R = Addenbrooke's Cognitive Examination - Revised; SE = standard error; ZBI = Zarit Burden Interview.

Adjusted R square $=0.54$. Reference categories: gender male; age 60-69 years, education $\geq 9$ years; non-frail caregivers; and $Z B \mathrm{BI}<16$. 


\section{Discussion}

This study confirmed that burden and frailty were associated with cognition in elders who provide daily and essential care for the survival of other seniors in a rural context. We demonstrated that being pre-frail or frail was associated with a decrease of global cognitive test scores, also confirming that burden is related to impaired cognitive performance independent of gender and age. We also observed that education was the strongest factor associated with cognitive performance on the cognitive battery.

Older caregivers in rural areas presented differences when compared to participants from urban settings assessed in other studies. Caregivers in rural areas have more help than urban caregivers. ${ }^{22,23}$ Spouse caregivers seem to take care for longer periods when compared to other family caregivers. In a recent study, most caregivers were children or children-in-law, and provided care for about 7 years. ${ }^{22}$

Functional disability of care recipients has been seen as a risk factor for severe burden in caregivers. Dementia caregiving is associated with high burden scores, thus dementia caregivers have more distress compared to caregivers of people with other disorders .2,23,24 Frailty conditions and cognitive impairment in older caregivers corroborate the findings of a previous review including 19 studies, at a total of 29,664 participants, in which the prevalence of cognitive impairment ranged from 16 to $25 \%$, and frailty reached $10 \%$, regardless of the way how it is described. ${ }^{25}$

The phenomenon observed in the present study reflects a complex relationship between cognitive functioning and frailty in elderly people. This association has been increasingly studied, and promising results in the area are expected. One of the concepts of this relationship is called cognitive frailty, which is a clinical condition characterized by the simultaneous occurrence of frailty and cognitive impairment, and the absence of a diagnosis of dementia or other neurological impairments. ${ }^{26,27}$ The present study is one of the first to examine the relationship between cognitive performance and frailty in older adults who serve as caregivers in a rural community.

No previous studies were found that assessed directly the association between burden and cognitive performance in older caregivers, but some studies have indicated that stress, which has been associated with burden, seems to play an important role in this association. Increased stress level are associated with rapid decline in cognitive function. ${ }^{28}$ Moreover, cognitive decline may occur up to $30 \%$ faster in people prone to stress and distress, ${ }^{29}$ and mnemonic functions may be mostly affected by high stress levels. ${ }^{5}$

More specific studies have used oxidative stress markers to reveal this association. Studies have shown that oxidative stress biomarker levels are considerably higher in people undergoing cognitive and emotional changes - interestingly, they were found to be higher in residents of urban areas compared to those living in rural areas. ${ }^{30}$ A Mexican study involving 104 urban elderly and 85 rural elderly revealed that the rural elders presented better cognitive performance and lower levels of lipid peroxides, an oxidative stress blood marker. In addition, individuals with cognitive impairment had higher levels of this marker in comparison to those who are cognitively preserved. ${ }^{31}$

A study with Japanese workers found that urinary oxidative stress marker levels were negatively associated with job skills, and when resources were offered to improve these skills, oxidative stress levels measured decreased considerably. ${ }^{32}$ Hence, care skills might be affected by stress levels. The lack of studies involving older caregivers limits data discussion. More research is needed on elders while experiencing caring roles in the family. Over $80 \%$ of elders help the family in any way, such as transport, domestic activities, food, caring for clothes and utensils, money and child care. ${ }^{33}$

Some reasons why burden has not been previously studied as a possible causal factor of cognitive impairment may be related to the way it is usually measured. In the present study, the scale was sensitive to assess this variable. Another point is the behavior of burden changes due to cognitive performance that might be hidden by other covariables. In our sample of caregivers living in rural areas, burden remained associated with decreased cognitive performance in the multiple regression, after being controlled for other covariables. Patients scoring 17-20 on ZBI should be thoroughly investigated, as this may be indicative of a risk for worse cognitive function among older caregivers.

In summary, the study showed that not only frailty but also high burden may be risk factors for cognitive performance decline in older caregivers living in rural areas. This study has some limitations. We were not able to provide a clinical evaluation of pre-clinical dementia during this study, which limits some of the interpretations. Moreover, despite having good internal consistency, the tool used to assess cognition needs normative data for different levels of education. Regression analysis in this study confirmed that schooling strongly influences performance on neuropsychological tests. ${ }^{20}$ 


\section{Conclusion}

A better understanding of the independent contribution of burden and frailty to cognition would allow to improve care management for both the caregiver and the care recipient. A combined assessment of burden, frailty, and cognitive performance may help identify a possible risk for disability in the caregiver. The findings presented here may help contribute towards a better understanding of cognitive frailty.

Older caregivers in rural settings work with the resources available. An important number of caregivers of elderly are over 60 years of age. Actions and resources to decrease burden and physical frailty may provide better cognitive performance and well-being. Moreover, they may improve quality of life and the quality of the care provided.

\section{Acknowledgements}

We thank to all the elders who participated in the study. This work was supported by Fundação de Amparo à Pesquisa do Estado de São Paulo (2013/26798-9; 2014/23898-5).

\section{References}

1. Brigola AG, Luchesi BM, Rossetti ES, Mioshi E, Inouye K, Pavarini $\mathrm{SCI}$, et al. Health profile of family caregivers of the elderly and its association with variables of care: a rural study. Rev Bras Geriatr Gerontol. 2017;20:409-20.

2. Pinquart M, Sorensen S. Associations of stressors and uplifts of caregiving with caregiver burden and depressive mood: a metaanalysis. J Gerontol B Psychol Sci Soc Sci. 2003;58:112-28.

3. Pinquart $M$, Sorensen S. Spouses, adult children, and childrenin-law as caregivers of older adults: a meta-analytic comparison. Psychol Aging. 2011;26:1-14

4. Pinquart M, Sorensen S. Gender differences in caregiver stressors, social resources, and health: an updated meta-analysis. J Gerontol B Psychol Sci Soc Sci. 2006;61:33-45.

5. Balardin JB, Palma KAXA, Garcia Junior ME, Bromberg E. Déficits cognitivos em cuidadores de pacientes com demência. Rev Bras Cienc Envelhec Hum. 2007; 4:55-64.

6. Robertson DA, Savva GM, Coen RF, Kenny R-A. Cognitive function in the prefrailty and frailty syndrome. J Am Geriatr Soc. 2014;62:2118-24.

7. Dumurgier J, Artaud F, Touraine C, Rouaud O, Tavernier B, Dufouil $C$, et al. Gait speed and decline in gait speed as predictors of incident dementia. J Gerontol A Biol Sci Med Sci. 2017;72:655-61.

8. Artaud F, Singh-Manoux A, Dugravot A, Tzourio C, Elbaz A. Decline in fast gait speed as a predictor of disability in older adults. J Am Geriatr Soc. 2015;63:1129-36.

9. Fried LP, Tangen CM, Walston J, Newman AB, Hirsch C, Gottdiener J, et al. Frailty in older adults: evidence for a phenotype. J Gerontol A Biol Sci Med Sci. 2001;56:146-56.

10. Instituto Brasileiro de Geografia e Estatística. Diretoria de Pesquisas, Coordenação de Trabalho e Rendimento. Pesquisa Nacional por Amostra de Domicílios 2013. Brasília: IBGE; 2013. http://www.ibge.gov.br/home/estatistica/populacao/ trabalhoerendimento/pnad2013/default_sintese.shtm

11. Travassos C, Viacava F. Acesso e uso de serviços de saúde em idosos residentes em áreas rurais, Brasil, 1998 e 2003. Cad Saude Publica. 2007;23:2490-502.
12. Chadiha LA, Feld S, Rafferty J. Likelihood of African American primary caregivers and care recipients receiving assistance from secondary caregivers: a rural-urban comparison. J App Gerontol. 2011;30:422-42.

13. Goins RT, Spencer SM, Byrsd JC. Research on rural caregiving: a literature review. J App Gerontol. 2009;28:139-70.

14. Innes $A$, Morgan $D$, Kosteniuk J. Dementia care in rural and remote settings: a systematic review of informal/family caregiving. Maturitas. 2011;68:34-46.

15. Pavarini SCI, Neri AL, Brigola AG, Ottaviani AC, Souza EN, Rossetti ES, et al. Elderly caregivers living in urban, rural and high social vulnerability contexts. Rev Esc Enferm USP. 2017;51:e03254.

16. Katz S, Ford AB, Moskowitz RW, Jackson BA, Jaffe MW. Studies of illness in the aged. The index of ADL: a standardized measure of biological and psychosocial function. JAMA. 1963;185:914-9.

17. Lawton MP, Brody EM. Assessment of older people: self-maintaining and instrumental activities of daily living. Gerontologist. 1969;9:179-86.

18. Mioshi E, Dawson K, Mitchell J, Arnold R, Hodges JR. The Addenbrooke's Cognitive Examination Revised (ACE-R): a brief cognitive test battery for dementia screening. Int J Geriatr Psychiatry. 2006;21:1078-85.

19. Folstein MF, Folstein SE, McHugh PR. "Mini-mental state". A practical method for grading the cognitive state of patients for the clinician. J Psychiatr Res. 1975;12:189-98.

20. Brucki SMD, Nitrini R, Caramelli P, Bertolucci PHF, Okamoto IH. Suggestions for utilization of the mini-mental state examination in Brazil. Arq Neuro-Psiquiatr. 2003;61:777-81.

21. Scazufca M. Brazilian version of the Burden Interview scale for the assessment of burden of care in carers of people with mental illnesses. Rev Bras Psiquiatr. 2002;24:12-7.

22. Valer DB, Aires M, Fengler FL, Paskulin LMG. Adaptation and validation of the Caregiver Burden Inventory for use with caregivers of elderly individuals. Rev Lat Am Enfermagem. 2015;23:130-8.

23. Gratão ACM, Vale F de AC do, Roriz-Cruz M, Haas VJ, Lange C, Talmelli LF da S, et al. The demands of family caregivers of elderly individuals with dementia. Rev Esc Enferm USP. 2010;44:87380.

24. Gratão ACM, Talmelli LF da S, Figueiredo LC, Rosset I, Freitas CP, Rodrigues RAP. Dependência funcional de idosos e a sobrecarga do cuidador. Rev Esc Enferm USP. 2013;47:137-44.

25. Brigola AG, Rossetti ES, Santos BR, Neri AL, Zazzetta MS, Inouye $\mathrm{K}$, et al. Relationship between cognition and frailty in elderly: a systematic review. Dement Neuropsychol. 2015;9:110-9.

26. Canevelli M, Cesari M. Cognitive frailty: what is still missing? J Nutr Health Aging. 2015;19:273-5.

27. Dartigues JF, Amieva $\mathrm{H}$. Cognitive frailty: rational and definition dorm an (IANA/IAGG) International consensus group. ] Nutr Health Aging. 2014;18:95.

28. Aggarwal NT, Wilson RS, Beck TL, Rajan KB, Mendes de Leon CF, Evans $D$ a, et al. Perceived stress and change in cognitive function among adults 65 years and older. Psychosom Med. 2014;76:805.

29. Wilson RS, Bennett DA, Mendes De Leon CF, Bienias JL, Morris MC, Evans DA. Distress proneness and cognitive decline in a population of older persons. Psychoneuroendocrinology. 2005;30:11-7.

30. Reyazuddin M, Azmi SA, Islam N, Rizvi A. Oxidative stress and level of antioxidant enzymes in drug-naive schizophrenics. Indian J Psychiatry. 2014;56:344-9.

31. Sánchez-Rodríguez $M$ a, Santiago $E$, Arronte-Rosales $A$, VargasGuadarrama LA, Mendoza-Núñez VM. Relationship between oxidative stress and cognitive impairment in the elderly of rural vs. urban communities. Life Sci. 2006;78:1682-7.

32. Ohta $M$, Kumashiro $M$, Eguchi $Y$, Morita $Y$, Konno $Y$, Yamato $H$. The relationship between work ability and oxidative stress in Japanese workers. Ergonomics. 2014;57:1265-73.

33. Bertuzzi D, Paskulin LMG, Morais EP de. Arranjos e rede de apoio familiar de idosos que vivem em uma área rural. Texto Context Enferm. 2012;21:158-66.

\section{Correspondence:}

Allan Gustavo Brigola

Rua Urias Cardoso de Toledo, 133, São Carlos V

135463528 - São Carlos, SP - Brazil

Tel.: +55 (16) 992212216

E-mail: allanbrig@gmail.com 